Editorial

\title{
Acknowledgement to Reviewers of Journal of Cardiovascular Development and Disease in 2017
}

\author{
JCDD Editorial Office \\ MDPI AG, St. Alban-Anlage 66, 4052 Basel, Switzerland; jcdd@mdpi.com \\ Published: 22 January 2018
}

Peer review is an essential part in the publication process, ensuring that Journal of Cardiovascular Development and Disease maintains high quality standards for its published papers. In 2017, a total of 24 papers were published in the journal. Thanks to the cooperation of our reviewers, the median time to first decision was 17.5 days and median APT was 43 days. The editors would like to express their sincere gratitude to the following reviewers for their time and dedication in 2017:

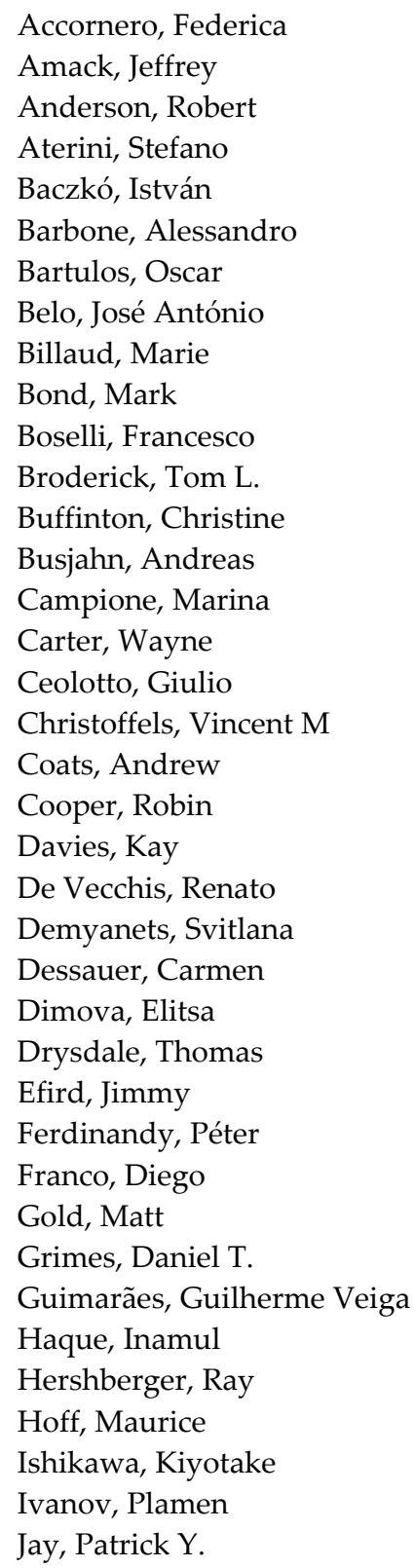

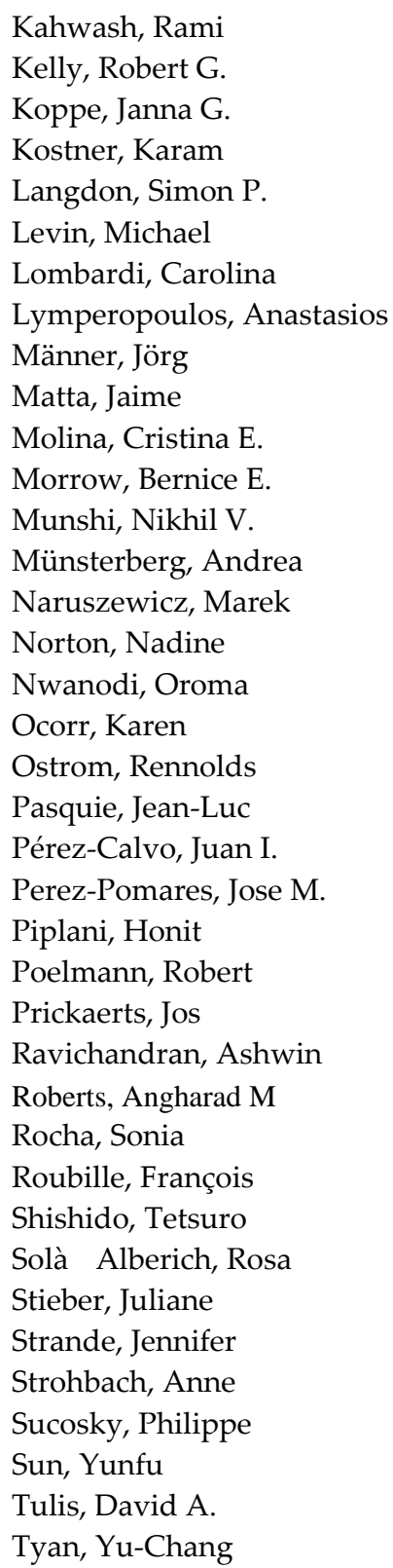


Jaźwińska, Anna

Jeremy, Richmond

Johnson, Erik

Joseph, Jacob

Jovanović, Aleksandar
Van Lieshout, Johannes J.

Wachten, Dagmar

Wessells, Robert

Xin, Mei

Yaniv, Yael

(C) 2018 by the author. Licensee MDPI, Basel, Switzerland. This article is an open access article distributed under the terms and conditions of the Creative Commons Attribution (CC-BY) license (http://creativecommons.org/licenses/by/4.0/). 